\title{
Phase II study of capecitabine and irinotecan combination chemotherapy in patients with advanced gastric cancer
}

\author{
JH Baek', JG Kim*,', SB Jeon', YS Chae', DH Kim', SK Sohn', KB Lee', YJ Choi ${ }^{2}$, HJ Shin ${ }^{2}$, JS Chung ${ }^{2}$, GJ Cho $^{2}$, \\ HY Jung ${ }^{3}$ and $W Y^{3}$
}

'Department of Oncology/Hematology, Kyungpook National University Hospital, Daegu, Korea; ${ }^{2}$ Department of Oncology/Hematology, Pusan National University Hospital, Pusan, Korea; ${ }^{3}$ Department of General Surgery, Kyungpook National University Hospital, Daegu, Korea

The present study was conducted to evaluate the efficacy and safety of a combination regimen of capecitabine plus irinotecan in patients with advanced gastric cancer. Patients with previously untreated metastatic or recurrent, measurable gastric cancer received oral capecitabine $1000 \mathrm{mg} \mathrm{m}^{-2}$ twice daily from day I to 14 and intravenous irinotecan $100 \mathrm{mg} \mathrm{m}^{-2}$ on days 1 and 8 , based on a 3 -week cycle. Forty-one patients were enrolled in the current study, among whom 38 were assessable for efficacy and 40 assessable for toxicity. Three complete responses and 16 partial responses were confirmed, giving an overall response rate of $46.3 \%$. At a median follow-up of 269 days, the median time to progression and overall survival were 5.1 and 8.6 months, respectively. Grade 3/4 neutropenia occurred in four patients and grade 3 febrile neutropenia was observed in two patients. Grade 3 diarrhoea and grade 2 hand-foot syndrome occurred in six patients and eight patients, respectively. The combination of capecitabine and irinotecan was found to be well tolerated and effective in patients with advanced gastric cancer. Accordingly, this regimen can be regarded as one of first-line treatment options for advanced gastric cancer.

British Journal of Cancer (2006) 94, |407- |4| I. doi: I0.1038/sj.bjc.6603093 www.bjcancer.com

Published online 25 April 2006

(c) 2006 Cancer Research UK

Keywords: capecitabine; chemotherapy; gastric cancer; irinotecan

Despite a declining incidence in many developed countries, gastric cancer remains the second most common cancer-related death in the world (Pisani et al, 1999). Although the prognosis for advanced gastric cancer is poor, combination chemotherapy has improved the quality of life and overall survival compared with the best supportive care in several randomised studies (Murad et al, 1993; Glimelius et al, 1994; Pyrhonen et al, 1995). Among the various active chemotherapeutic agents, cisplatin-based combination chemotherapy has been most commonly used with a high response rate of 48-56\% (Kim et al, 1993; Boku et al, 1999; Roth et al, 2000). Yet, notwithstanding its active anticancer effect in the treatment of advanced gastric cancer, cisplatin also induces nausea and vomiting in most patients (Boku et al, 1999; Roth et al, 2000). Plus, despite the development of new antiemetic agents, nausea and vomiting are still the main treatment-interrupting complications.

As such, oral fluoropyrimidine capecitabine (Xeloda ${ }^{\mathrm{R}}$; HoffmannLa Roche Inc., Nutley, NJ, USA) was rationally designed to preferentially generate 5-FU in tumour tissue and mimic continuous-infusion 5-FU. This tumour selectivity is achieved through exploiting the significantly higher activity of thymidine phosphorylase in many tumour tissues compared with healthy tissue (Miwa et al, 1998; Schuller et al, 2000). In addition, capecitabine has also exhibited antitumour activity with tolerable

*Correspondence: Dr JG Kim; E-mail: jkk2 Ic@mail.knu.ac.kr Received 3 January 2006; revised 13 March 2006; accepted 13 March 2006; published online 25 April 2006 safety profiles when given as a monotherapy or in combination with cisplatin in patients with various other solid tumours as well as advanced gastric cancer (Kim et al, 2002; Ahn et al, 2003; Koizumi et al, 2003).

Meanwhile, irinotecan is a semisynthetic, water-soluble derivative of the plant alkaloid camptothecin. After conversion to its active metabolite, SN-38, irinotecan acts by inhibiting the enzyme DNA-topoisomerase I. Irinotecan has also shown promising activity in advanced gastric cancer as a single agent or combined with other agents (Boku et al, 1999; Ajani et al, 2001; Bugat, 2003).

The combination of capecitabine plus irinotecan has already shown synergistic antitumour activity in preclinical and clinical studies (Cassata et al, 2001; Jordan et al, 2002), where preclinical evidence indicated that irinotecan upregulates thymidine phosphorylase expression (Jordan et al, 2002), possibly providing the basis for the synergistic antitumour activity of the capecitabine and irinotecan combination. Furthermore, capecitabine and irinotecan have distinct action mechanisms and only partially overlapping adverse event profiles.

Although several studies have shown the efficacy and safety of capecitabine and irinotecan for advanced colorectal cancer (Tewes et al, 2003; Bajetta et al, 2004; Borner et al, 2005; Kim et al, 2005; Rea et al, 2005), no results have yet been reported for advanced gastric cancer. Accordingly, the current phase II study was conducted to evaluate the efficacy and safety of a combination regimen of capecitabine plus irinotecan in patients with advanced gastric cancer. 


\section{PATIENTS AND METHODS}

\section{Eligibility}

All the patients involved in the current study had histologically confirmed metastatic or recurrent gastric adenocarcinoma with at least one unidimensionally measurable lesion. The patients were 18-75 years of age with a performance status of $0-2$ on the Eastern Cooperative Oncology Group (ECOG) scale. Also, adequate haematological (absolute neutrophil count $\geqslant 1.5 \times 10^{9} 1^{-1}$, platelet count $\geqslant 100 \times 10^{9} \mathrm{l}^{-1}$, and haemoglobin $\geqslant 9 \mathrm{~g} \mathrm{dl}^{-1}$ ), renal (serum creatinine $\leqslant 1.5 \mathrm{mg} \mathrm{dl}^{-1}$ and creatinine clearance $\geqslant 50 \mathrm{ml} \mathrm{min}^{-1}$ ), and hepatic (total bilirubin $\leqslant 1.5 \mathrm{mg} \mathrm{dl}^{-1}$ and serum transaminase level $\leqslant 2.5$ times the upper normal limit (UNL) or $\leqslant 5$ times the UNL in cases of hepatic metastases) functions were also required. Patients were ineligible if they had previously received palliative chemotherapy or radiation therapy, or had other severe medical illnesses, CNS metastasis, or another active malignancy. The protocol was approved by the institutional review board of each centre, and written informed consent obtained from all patients before enrolment. The ethical opinion was also considered by the institutional review board.

\section{Study treatment}

All the treatments were administered on an outpatient basis. Capecitabine $1000 \mathrm{mg} \mathrm{m}^{-2}$ b.i.d. with pyridoxine $100 \mathrm{mg}$ t.i.d. was given on days 1-14 followed by a 7-day rest period. The capecitabine was supplied as film-coated tablets at two dose strengths, 150 and $500 \mathrm{mg}$, whereas the irinotecan $100 \mathrm{mg} \mathrm{m}^{-2}$ was administered through a 90 -min intravenous infusion on days 1 and 8 , based on a 3 -week cycle. All patients received $5-\mathrm{HT}_{3}$ inhibitors for emesis prophylaxis. Treatment was continued until disease progression, patient refusal, or an unacceptable toxicity with a maximum of nine cycles.

\section{Dose modification}

The next course of treatment only began when the neutrophil count was $\geqslant 1.5 \times 10^{9} 1^{-1}$, the platelet count was $\geqslant 75 \times 10^{9} 1^{-1}$, and any other treatment-related toxicities were less than or equal to grade 1; otherwise, treatment was withheld for up to 2 weeks. If adverse events did not improve to grade 0 or 1 after 3 weeks, the patients were excluded from the study.

The capecitabine treatment within a particular cycle was withheld in the presence of repeated grade 2 or any grade $\geqslant 3$ haematological or non-haematological toxicity. The capecitabine treatment was then resumed at a $25 \%$ dose reduction after a resolution of the toxicity to grade $0-1$. An additional $25 \%$ dose reduction was also applied in the case of repeated grade $\geqslant 3$ toxicity. For grade $2-3$ hand-foot syndrome (HFS), the capecitabine treatment was withheld until a resolution to less than or equal to grade 1 , then restarted with a $25 \%$ dose reduction.

The irinotecan treatment on day 8 was omitted in the presence of grade $\geqslant 3$ haematological or non-haematological toxicity on the day scheduled for the irinotecan administration, and the patient then re-evaluated weekly until regressing to less than or equal to grade 1. Missed doses of irinotecan were not made up. The following cycle of treatment was reduced by $25 \%$ in the case of repeated grade 2 or any grade 3 toxicity and reduced by $50 \%$ in the case of repeated grade 3 or any grade 4 toxicity during the preceding cycle.

\section{Study assessments}

A screening assessment, including the medical history, a physical examination, ECG, chest X-ray, and tumour assessment, was conducted within 2 weeks before starting the treatment. Further assessments conducted within 7 days before starting the treatment included vital signs, an ECOG performance status, and laboratory tests (haematology, blood chemistry, and urinalysis). Complete blood counts were performed before and on day 8 of each cycle, and biochemical tests performed before each cycle. The tumours were measured by computed tomography (CT) scans every three cycles until the tumour progressed. The tumour responses were classified according to the response evaluation criteria in solid tumours (RECIST) guidelines (Therasse et al, 2000) complete response (CR), the disappearance of all target lesions; partial response (PR), a decrease of at least $30 \%$ in the sum of the longest diameters of the target lesions; progressive disease (PD), an increase of at least $20 \%$ in the sum of the longest diameters of the target lesions or the appearance of one or more new lesions; stable disease (SD), neither sufficient shrinkage to qualify for PR nor a sufficient increase to qualify for PD. Complete response or PR patients were required to undergo a confirmatory disease assessment at least 4 weeks later. Adverse events were graded according to the National Cancer Institute Common Toxicity Criteria for Adverse Events (NCI-CTCAE) version 3.0; HFS was graded $1-3$, as defined in previous capecitabine clinical studies (Blum et al, 1999).

\section{Statistical analysis}

The current trial was designed to detect a response rate of $40 \%$ as compared to a minimal, clinically meaningful response rate of $20 \%$. Plus, the current trial used a two-stage optimal MiniMax design, as proposed by Simon, (1989), with an $80 \%$ power to accept the hypothesis and 5\% significance to reject the hypothesis (Simon, 1989). Allowing for a follow-up loss rate of $10 \%$, the total sample size was 37 patients with a measurable disease. The duration of response, time to progression (TTP), and survival analysis were estimated using the Kaplan-Meier method. The duration of response was defined as the interval from the onset of CR or PR until evidence of PD was found. Meanwhile, the time to progression was calculated from the initiation of chemotherapy to the date of disease progression, and the overall survival measured from the initiation of chemotherapy to the date of the last followup or death. The statistical data were obtained using an SPSS software package (SPSS 11.5 Inc., Chicago, IL, USA).

\section{RESULTS}

\section{Patient characteristics}

Between July 2004 and March 2005, 41 patients were enrolled in the present study from two centres. The characteristics of the patients are summarised in Table 1. The median age was 59.0 (range: 2574) years, and there were 30 men and 11 women. Most of the patients $(92.7 \%)$ had a good performance status (ECOG 0 or 1 ). Twenty-nine $(70.7 \%)$ patients were suffering from a metastatic disease, whereas 12 patients had a recurrent disease after surgical resection (total or subtotal gastrectomy) of the primary tumour. Distal lymph nodes and the liver were the most common sites of the metastases.

\section{Efficacy}

Thirty-eight of the 41 patients (92.7\%) were assessable for response, with the remaining three being lost to follow-up or patient refusal. All efficacy data are reported using the intentionto-treat patient population. Three cases of CR and 16 cases of PR were confirmed, giving an overall response rate of $46.3 \%$ (95\% CI: $30.4-62.3 \%$ ). The response characteristics are shown in Table 2. The median duration of response in the 19 responding patients was 4.6 months (95\% CI: 3.3-5.9 months), whereas the median TTP for all patients was 5.1 months (95\% CI: 3.9-6.3 months) at a 
Table I Patient characteristics

\begin{tabular}{|c|c|}
\hline Characteristic & $\begin{array}{c}\text { Number of } \\
\text { patients }(N=41, \%)\end{array}$ \\
\hline \multicolumn{2}{|l|}{ Age (years) } \\
\hline Median & 59 \\
\hline Range & $25-74$ \\
\hline \multicolumn{2}{|l|}{ Gender } \\
\hline Male & $30(73.2)$ \\
\hline Female & II (26.8) \\
\hline \multicolumn{2}{|l|}{ ECOG performance status } \\
\hline 0 & | (2.4) \\
\hline I & $37(90.2)$ \\
\hline 2 & $3(7.3)$ \\
\hline \multicolumn{2}{|l|}{ Disease status } \\
\hline Metastatic & $29(70.7)$ \\
\hline Recurrent & $12(29.3)$ \\
\hline \multicolumn{2}{|l|}{ Location of primary tumour } \\
\hline Upper & $8(19.5)$ \\
\hline Middle & I| (26.8) \\
\hline Lower & $22(53.7)$ \\
\hline \multicolumn{2}{|l|}{ Histology } \\
\hline Adenocarcinoma, well differentiated & $3(7.3)$ \\
\hline Adenocarcinoma, moderately differentiated & $13(31.7)$ \\
\hline Adenocarcinoma, poorly differentiated & $25(61.0)$ \\
\hline \multicolumn{2}{|l|}{ Metastatic sites } \\
\hline Liver & $21(32.8)$ \\
\hline Peritoneum & $10(15.6)$ \\
\hline Distal lymph nodes & $22(34.4)$ \\
\hline Ovary & $6(9.4)$ \\
\hline Others (lung, bone, uterus, and spleen) & $5(7.8)$ \\
\hline \multicolumn{2}{|l|}{ Number of metastatic sites } \\
\hline । & $21(51.2)$ \\
\hline 2 & $19(46.3)$ \\
\hline$\geqslant 3$ & I (2.4) \\
\hline
\end{tabular}

Table 2 Tumour response (intention-to-treat analysis)

\begin{tabular}{lc}
\hline Response & Number $(\boldsymbol{n}=\mathbf{4 1}, \mathbf{\%})$ \\
\hline Confirmed response & $19(46.3)^{\mathrm{a}}$ \\
Complete response & $3(7.3)$ \\
Partial response & $16(39.0)$ \\
Stable disease & $6(14.6)$ \\
Progressive disease & $13(31.7)$ \\
Not assessable & $3(7.3)$ \\
\hline
\end{tabular}

${ }^{a} 95 \% \mathrm{Cl}=30.4-62.3 \%$.

median follow-up duration of 269 days (range: 13-519 days). Twenty-seven patients had died at the time of the present evaluation. The median overall survival was 8.6 months (95\% CI: $6.1-11.1$ months) with a 1-year survival rate of $32.6 \%$ (Figure 1).

\section{Toxicity}

The haematological and non-haematological toxicities that occurred during the current study are summarised in Table 3. A total of 160 cycles (median 3, range 1-9 cycles) were administrated in 40 patients assessable for toxicity. The most severe haematological adverse event was neutropenia, which occurred with a grade $3 / 4$ intensity in four patients $(10.0 \%)$ in seven cycles $(4.4 \%)$. Plus, febrile neutropenia was observed in two patients (5.0\%). All cases were successfully treated with antibiotics and G-CSF, and there

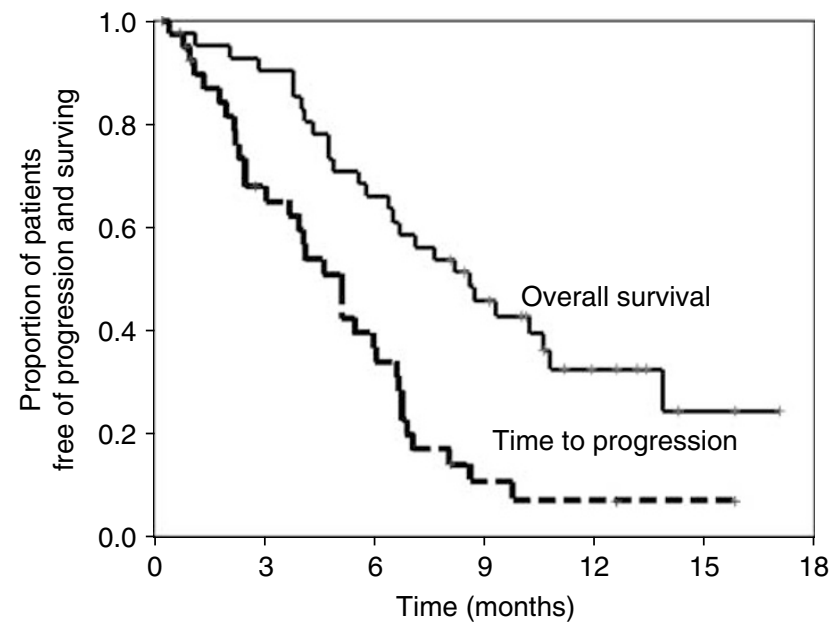

Figure I Kaplan-Meier curves for time to disease progression and overall survival for intention-to-treat population $(n=41)$.

were no treatment-related deaths during this study. The most common non-haematological toxicity was nausea (grade $1 / 2$, $80.0 \%)$. Grade 3 diarrhoea occurred in six patients (15.0\%) and grade 2 HFS, a complication of capecitabine, occurred in four patients $(10.0 \%)$. Yet, no grade 4 non-haematological toxicity was observed. Overall, $10(25.0 \%)$ patients and 27 (16.9\%) cycles required a dose reduction of irinotecan on day 1 , whereas dose omissions of irinotecan on day 8 were needed in $18(11.3 \%)$ cycles. Also, a total of eight $(5.0 \%)$ cycles were delayed. The most common reasons for the dose modification of irinotecan were neutropenia (eight patients, 13 cycles) and diarrhoea (nine patients, 11 cycles). Meanwhile, the capecitabine doses were modified mainly owing to neutropenia, diarrhoea, or HFS. The mean dose intensity over all the treatment cycles was $8641 \mathrm{mg} \mathrm{m}^{-2}$ week $^{-1}$ for capecitabine and $58.4 \mathrm{mg} \mathrm{m}^{-2}$ week $^{-1}$ for irinotecan, corresponding to 92.6 and $87.6 \%$ of the planned dose intensity, respectively. The compliance with capecitabine was $96.0 \%$ for all the treatment cycles.

\section{DISCUSSION}

In the current study, the combination chemotherapy of capecitabine and irinotecan, which can be administered on an outpatient basis, produced active antitumour activity and a safe toxicity profile in patients with advanced gastric cancer. The overall response rate $(46.3 \%)$, median TTP (5.1 months), and median overall survival ( 8.6 months) following treatment with the present regimen were comparable with previous results reported for cisplatin-based combinations (Kim et al, 1993; Boku et al, 1999; Roth et al, 2000; Vanhoefer et al, 2001), where a continuous infusion of a 5-FU and cisplatin regimen achieved a response rate of $37-51 \%$ and median overall survival of 9-9.7 months (Kim et al, 1993; Vanhoefer et al, 2001), whereas docetaxel or irinotecan plus cisplatin regimens achieved a response rate and median overall survival of $48-56 \%$ and 9-9.06 months, respectively (Boku et al, 1999; Roth et al, 2000).

Recently, in meta-analysis for advanced gastric cancer (Wagner et al, 2005), combination chemotherapy improved survival compared to single-agent 5-FU, and best survival results were achieved with regimens containing 5-FU, anthracycline, and cisplatin among the various combination chemotherapies. However, Dank et al (2005) reported that irinotecan plus 5-FU/folinic acid showed a trend to TTP superiority, compared with cisplatin and 5-FU, as well as a better safety profile in a randomised phase III trial. And they suggested that irinotecan plus 5-FU/folinic acid 


\begin{tabular}{|c|c|c|c|c|c|c|c|c|}
\hline & \multicolumn{4}{|c|}{ Grade $^{\mathrm{a}}(\%$ of patients, $n=40)$} & \multicolumn{4}{|c|}{ Grade $^{a}(\%$ of cycles, $n=160)$} \\
\hline & $\mathbf{I}$ & 2 & 3 & 4 & $\mathbf{I}$ & 2 & 3 & 4 \\
\hline Anaemia & 35.0 & 30.0 & 2.5 & & 30.0 & 11.3 & 1.3 & \\
\hline Leukopenia & 10.0 & 22.5 & 5.0 & 2.5 & 13.1 & 10.6 & 2.5 & 0.6 \\
\hline Neutropenia & 12.5 & 27.5 & 7.5 & 2.5 & 15.0 & 12.5 & 3.8 & 0.6 \\
\hline Thrombocytopenia & 5.0 & & & & 0.6 & & & \\
\hline Anorexia & 22.5 & 17.5 & 2.5 & & 10.6 & 6.3 & 0.6 & \\
\hline Nausea & 60.0 & 20.0 & 2.5 & & 25.0 & 9.4 & 0.6 & \\
\hline Vomiting & 15.0 & 30.0 & 5.0 & & 11.9 & 9.4 & 1.9 & \\
\hline Stomatitis & 25.0 & 10.0 & 2.5 & & 10.6 & 8.1 & 0.6 & \\
\hline Diarrhoea & 22.5 & 20.0 & 15.0 & & 11.3 & 6.9 & 5.0 & \\
\hline Constipation & 10.0 & 2.5 & & & 3.8 & 0.6 & & \\
\hline Abdominal pain & 15.0 & 2.5 & & & 5.6 & 0.6 & & \\
\hline
\end{tabular}

${ }^{a} \mathrm{NCl}-\mathrm{CTCAE}$ v3.0, except for grading of hand-foot syndrome.

could be an alternative first-line treatment option without cisplatin for patients with advanced gastric cancer.

Capecitabine has already been shown to be active and safe in the treatment of previously untreated advanced gastric cancer. A recent phase II study by Kim et al (2002) reported that a capecitabine plus cisplatin regimen produced a high response rate of $54.8 \%$ and median overall survival of 10.1 months in patients with advanced gastric cancer. In contrast, the current study used a reduced dose of capecitabine, $1000 \mathrm{mg} \mathrm{m}^{-2}$ instead of $1250 \mathrm{mg} \mathrm{m}^{-2}$, owing to the relatively high incidence of HFS. Grade $2 / 3$ HFS has previously been observed in $27.5-50 \%$ of patients with advanced gastric cancer who received the standard dose of capecitabine (Kim et al, 2002; Park et al, 2004), and as there is no effective prophylaxis or treatment for HFS, this can interrupt treatment or reduce the dose intensity of capecitabine. In the present trial, only four patients (10.0\%) experienced grade 2 HFS, allowing the dose intensity of capecitabine to reach $92.6 \%$.

The major toxicities related to irinotecan are diarrhoea and myelosuppression, which are known to be dose-dependent. Chemotherapy-induced severe diarrhoea or neutropenia can also result in treatment-related hospitalisation or mortality, thereby compromising the quality of life and increasing medical expenditure. Ajani et al (2002) reported that the weekly administration of irinotecan $\left(65 \mathrm{mg} \mathrm{m}^{-2}\right)$ and cisplatin $\left(30 \mathrm{mg} \mathrm{m}^{-2}\right)$ for 4 consecutive weeks followed by a 2-week break showed active antitumour activity in patients with untreated, advanced adenocarcinoma of the stomach or gastroesophageal junction. However, in their study, $27 \%$ of the patients experienced grade $3 / 4$ neutropenia and $22 \%$ experienced grade $3 / 4$ diarrhoea. Thus, owing to the high incidence of toxicities and treatment interruptions, they suggested that modification of the doses and schedule might be warranted to make the regimen more tolerable to patients. The combination regimen of irinotecan $\left(80 \mathrm{mg} \mathrm{m}^{-2}\right)$ followed by folinic acid $\left(500 \mathrm{mg} \mathrm{m}^{-2}\right)$ and 5 -FU (2000 $\mathrm{mg} \mathrm{m}^{-2}$ i.v. over $22 \mathrm{~h}$ ) weekly for 6 weeks also showed $25 \%$ of grade $3 / 4$ neutropenia, $5 \%$ of febrile neutropenia, and $22 \%$ of grade $3 / 4$ diarrhoea in a randomised trial (Dank et al, 2005).

Recently, in a randomised multicentre phase II trial (Bajetta et al, 2004) comparing two different schedules of irinotecan combined with capecitabine as the first-line treatment for metastatic colorectal cancer, diarrhoea, which occurred in $37.8 \%$ of the patients at a grade 3/4 intensity, was the main adverse effect of the arm B regimen (capecitabine $1000 \mathrm{mg} \mathrm{m}^{-2}$ twice daily on days $2-15$ and irinotecan $120 \mathrm{mg} \mathrm{m}^{-2}$ on days 1 and 8 , every 21 days). However, in the present study, a reduced dose of irinotecan $\left(100 \mathrm{mg} \mathrm{m}^{-2}\right.$ on days 1 and 8 ) was administered to alleviate adverse effects, and grade $3 / 4$ diarrhoea and neutropenia was only observed in 15 and $10 \%$ of the patients, respectively. Furthermore, there was no treatment-related death or grade 4 non-haematological adverse event.

In case of an irinotecan and 5-FU combination, the schedule-dependent interactions with respect to toxicity have already been demonstrated. Thus, a schedule of irinotecan followed by 5-FU infusion was found to be less toxic than the reversed schedule, and explained by a reduced $\mathrm{SN}-38$ area under the curve level when the irinotecan preceded the infusional 5-FU (Falcone et al, 2001). Accordingly, in the present study, the irinotecan infusion preceded the capecitabine medication. As such, the better tolerability of the present regimen may have been associated with the schedule-dependent interaction between capecitabine and irinotecan.

In conclusion, the combination of capecitabine and irinotecan was found to be well tolerated and effective in patients with advanced gastric cancer. Accordingly, this regimen can be regarded as one of first-line treatment options for advanced gastric cancer.

\section{REFERENCES}

Ahn MJ, Oh HS, Choi JH, Lee YY, Kim IS, Choi IY, Lee OY, Lee HW (2003) Combination chemotherapy of oxaliplatin and capecitabine in patients with metastatic colorectal cancer: a pilot study. Cancer Res Treat 35: 407-410
Ajani JA, Baker J, Pisters PW, Ho L, Feig B, Mansfield PF (2001) Irinotecan plus cisplatin in advanced gastric or gastroesophageal junction carcinoma. Oncology (Williston Park) 15: $52-54$ 
Ajani JA, Baker J, Pisters PW, Ho L, Mansfield PF, Feig BW, Charnsangavej C (2002) CPT-11 plus cisplatin in patients with advanced, untreated gastric or gastroesophageal junction carcinoma: results of a phase II study. Cancer 94: 641-646

Bajetta E, Di Bartolomeo M, Mariani L, Cassata A, Artale S, Frustaci S, Pinotti G, Bonetti A, Carreca I, Biasco G, Bonaglia L, Marini G, Iannelli A, Cortinovis D, Ferrario E, Beretta E, Lambiase A, Buzzoni R (2004) Randomized multicenter Phase II trial of two different schedules of irinotecan combined with capecitabine as first-line treatment in metastatic colorectal carcinoma. Cancer 100: 279-287

Blum JL, Jones SE, Buzdar AU, LoRusso PM, Kuter I, Vogel C, Osterwalder B, Burger HU, Brown CS, Griffin T (1999) Multicenter phase II study of capecitabine in paclitaxel-refractory metastatic breast cancer. J Clin Oncol 17: 485-493

Boku N, Ohtsu A, Shimada Y, Shirao K, Seki S, Saito H, Sakata Y, Hyodo I (1999) Phase II study of a combination of irinotecan and cisplatin against metastatic gastric cancer. J Clin Oncol 17: 319-323

Borner MM, Bernhard J, Dietrich D, Popescu R, Wernli M, Saletti P, Rauch D, Herrmann R, Koeberle D, Honegger H, Brauchli P, Lanz D, Roth AD (2005) A randomized phase II trial of capecitabine and two different schedules of irinotecan in first-line treatment of metastatic colorectal cancer: efficacy, quality-of-life and toxicity. Ann Oncol 16: 282-288

Bugat R (2003) Irinotecan in the treatment of gastric cancer. Ann Oncol 14(Suppl 2): ii37-ii40

Cassata A, Stani SC, Alu M, Procopio G, Cortinovis D, Beretta E, Ferrario E, Longarini R, Baldini A, Lambiase A, Di Bartolomeo M, Buzzoni R, Bidoli $\mathrm{P}$, Bajetta E (2001) Ongoing phase II trial with two schedules of irinotecan (CPT-11) in combination with capecitabine as first line chemotherapy in patients with advanced colorectal cancer (ACRC). Proc Am Soc Clin Oncol 20: 144a

Dank M, Zaluski J, Barone C, Valvere V, Peschel C, Wenczl M, Goker E, Risse M, Awad L, Bugat R (2005) Ranadomized phase 3 trial of irinotecan $(\mathrm{CPT} 11)+5 \mathrm{FU} /$ folinic acid (FA) $v s \mathrm{CDDP}+5 \mathrm{FU}$ in 1 st-line advanced gastric cancer patients. J Clin Oncol 23: 308s

Falcone A, Di Paolo A, Masi G, Allegrini G, Danesi R, Lencioni M, Pfanner E, Comis S, Del Tacca M, Conte P (2001) Sequence effect of irinotecan and fluorouracil treatment on pharmacokinetics and toxicity in chemotherapy-naive metastatic colorectal cancer patients. J Clin Oncol 19: $3456-3462$

Glimelius B, Hoffman K, Haglund U, Nyren O, Sjoden PO (1994) Initial or delayed chemotherapy with best supportive care in advanced gastric cancer. Ann Oncol 5: 189-190

Jordan K, Grothey A, Kellner A, Constantin C, Dietrich G, Schlichting C, Mantovani L, Kreoning H, Hagen V, Gutberlet K, Forstbauer H, Schmoll HJ (2002) Randomized phase II trial of capecitabine plus irinotecan vs capecitabine plus oxaliplatin as first-line therapy in advanced colorectal cancer (ACRC): results of an interim analysis. Proc Am Soc Clin Oncol 21: 103b

Kim NK, Park YS, Heo DS, Suh C, Kim SY, Park KC, Kang YK, Shin DB, Kim HT, Kim HJ, Kang WK, Suh CI, Bang YJ (1993) A phase III randomized study of 5-fluorouracil and cisplatin versus 5-fluorouracil, doxorubicin, and mitomycin $\mathrm{C}$ versus 5 -fluorouracil alone in the treatment of advanced gastric cancer. Cancer 71: 3813-3818

Kim TW, Kang YK, Ahn JH, Chang HM, Yook JH, Oh ST, Kim BS, Lee JS (2002) Phase II study of capecitabine plus cisplatin as first-line chemotherapy in advanced gastric cancer. Ann Oncol 13: 1893-1898

Kim TW, Kang WK, Chang HM, Park JO, Ryoo BY, Ahn JS, Zang DY, Lee KH, Kang YK, Kim SR, Kim HK (2005) Multicenter phase II study of oral capecitabine plus irinotecan as first-line chemotherapy in advanced colorectal cancer: a Korean Cancer Study Group trial. Acta Oncol 44: $230-235$

Koizumi W, Saigenji K, Ujiie S, Terashima M, Sakata Y, Taguchi T (2003) A pilot phase II study of capecitabine in advanced or recurrent gastric cancer. Oncology 64: $232-236$

Miwa M, Ura M, Nishida M, Sawada N, Ishikawa T, Mori K, Shimma N, Umeda I, Ishitsuka H (1998) Design of a novel oral fluoropyrimidine carbamate, capecitabine, which generates 5 -fluorouracil selectively in tumours by enzymes concentrated in human liver and cancer tissue. Eur I Cancer 34: 1274-1281

Murad AM, Santiago FF, Petroianu A, Rocha PR, Rodrigues MA, Rausch M (1993) Modified therapy with 5-fluorouracil, doxorubicin, and methotrexate in advanced gastric cancer. Cancer 72: 37-41

Park YH, Ryoo BY, Choi SJ, Kim HT (2004) A phase II study of capecitabine and docetaxel combination chemotherapy in patients with advanced gastric cancer. Br J Cancer 90: 1329-1333

Pisani P, Parkin DM, Bray F, Ferlay J (1999) Estimates of the worldwide mortality from 25 cancers in 1990. Int J Cancer 83: 18-29

Pyrhonen S, Kuitunen T, Nyandoto P, Kouri M (1995) Randomised comparison of fluorouracil, epidoxorubicin and methotrexate (FEMTX) plus supportive care with supportive care alone in patients with nonresectable gastric cancer. Br J Cancer 71: 587-591

Rea DW, Nortier JW, Ten Bokkel Huinink WW, Falk S, Richel DJ, Maughan T, Groenewegen G, Smit JM, Steven N, Bakker JM, Semiond D, Kerr DJ, Punt CJ (2005) A phase I/II and pharmacokinetic study of irinotecan in combination with capecitabine as first-line therapy for advanced colorectal cancer. Ann Oncol 16: 1123-1132

Roth AD, Maibach R, Martinelli G, Fazio N, Aapro MS, Pagani O, Morant R, Borner MM, Herrmann R, Honegger H, Cavalli F, Alberto P, Castiglione M, Goldhirsch A (2000) Docetaxel (Taxotere) - cisplatin (TC): an effective drug combination in gastric carcinoma. Swiss Group for Clinical Cancer Research (SAKK), and the European Institute of Oncology (EIO). Ann Oncol 11: 301-306

Schuller J, Cassidy J, Dumont E, Roos B, Durston S, Banken L, Utoh M, Mori K, Weidekamm E, Reigner B (2000) Preferential activation of capecitabine in tumor following oral administration to colorectal cancer patients. Cancer Chemother Pharmacol 45: 291-297

Simon R (1989) Optimal two-stage designs for phase II clinical trials. Control Clin Trials 10: 1-10

Tewes M, Schleucher N, Achterrath W, Wilke HJ, Frings S, Seeber S, Harstrick A, Rustum YM, Vanhoefer U (2003) Capecitabine and irinotecan as first-line chemotherapy in patients with metastatic colorectal cancer: results of an extended phase I study. Ann Oncol 14: $1442-$ 1448

Therasse P, Arbuck SG, Eisenhauer EA, Wanders J, Kaplan RS, Rubinstein L, Verweij J, Van Glabbeke M, van Oosterom AT, Christian MC, Gwyther SG (2000) New guidelines to evaluate the response to treatment in solid tumors. European Organization for Research and Treatment of Cancer, National Cancer Institute of the United States, National Cancer Institute of Canada. J Natl Cancer Inst 92: 205-216

Vanhoefer U, Wagner T, Lutz M, Van Cutsem E, Nordlinger B, Reuse S, Baron B, Wilke H, Wils J (2001) Randomized phase II study of weekly $24 \mathrm{~h}$ infusion of high dose 5 -FU \pm folinic acid (HD-FU $\pm \mathrm{FA}$ ) versus HDFU/FA/biweekly cisplatin in advanced gastric cancer. EORTC-trial 40953. Eur J Cancer 37: S27

Wagner AD, Grothe W, Behl S, Kleber G, Grothey A, Haerting J, Fleig WE (2005) Chemotherapy for advanced gastric cancer. Cochrane Database Syst Rev, CD004064 